\title{
LETTER
}

\section{Permissive hypofiltration: an alternative view}

\author{
Zaccaria Riccil,*, Stefano Romagnoli and Francesco Emma ${ }^{3}$ \\ See related viewpoint by Chawla et al., http://ccforum.com/content/16/4/317
}

\begin{abstract}
If permissive hypercapnia is used in the context of protective ventilation for patients with acute respiratory distress syndrome, it must be highlighted that the alveoli in these patients are still exposed to significant stress. Similarly, early renal replacement therapy is not necessarily a protective therapy for acute kidney injury and loop diuretics are not necessarily harmful. It is conceivable that early initiation of 'protective' low-dose $(10 \mathrm{ml} / \mathrm{kg} / \mathrm{h})$ continuous renal replacement therapy with zero balanced ultrafiltration in association with administration of (high dose) diuretics may help to rest the kidneys while ensuring preservation of urine output.
\end{abstract}

We read with great interest the Viewpoint by Chawla and colleagues [1] addressing the intriguing physiopathological hypothesis that resting a failing organ is potentially helpful to promote recovery. The authors proposed a 'permissive' therapy for acute kidney injury (AKI) by resting the kidneys with early renal replacement therapy (RRT), somewhat similar to treatment of acute respiratory distress syndrome with early intubation and permissive hypercapnia during 'protective' mechanical ventilation. During mechanical ventilation, however, rather than being at rest, alveoli are exposed to significant stress injuries (ventilator-induced lung injury) even under 'protective' ventilation [2]. Similarly, although early initiation of RRT could be beneficial, it should be emphasized that the advantage of such therapies over a 'conservative strategy' has not been consistently demonstrated to date, and that RRT also carries the risk of significant side effects that should not be overlooked [3], as also clearly pointed out by Chawla and colleagues.

\footnotetext{
*Correspondence: z.ricci@libero.it

'Pediatric Cardiac Anesthesia/Intensive Care Unit, Department of Pediatric Cardiology and Cardiac Surgery, Bambino Gesù Children's Hospital, IRCCS, Piazza S.Onofrio 4, 00165, Rome, Italy

Full list of author information is available at the end of the article
}

This may be particularly relevant when treating very young patients, which are often challenging from the standpoints of vascular accesses and fluid balance [4]. Furthermore, early initiation of extracorporeal ultrafiltration in patients with non-oliguric AKI might cause decreased urine output, a clearly undesired and detrimental effect. On the other side, to date, it has not convincingly been shown whether loop diuretics are harmful in the setting of AKI [5] and 'for the vast majority of clinicians' they are not generally discontinued in early AKI.

For acute respiratory distress syndrome therapy, extracorporeal carbon dioxide removal associated with ultraprotective ventilation has recently been proposed [6]. With a similar approach, it is conceivable that early initiation of 'protective' low-dose $(10 \mathrm{ml} / \mathrm{kg} / \mathrm{h})$ continuous RRT with zero balanced ultrafiltration in association with administration of (high dose) diuretics may help to rest the kidneys, while ensuring preservation of urine output. We believe that studies aimed at testing this hypothesis and establishing the best combination and doses of intravenous diuretics and 'protective' RRT are warranted.

\section{Abbreviations}

AKI, acute kidney injury; RRT, renal replacement therapy.

\section{Competing interests}

The authors declare that they have no competing interests.

\section{Author details}

'Pediatric Cardiac Anesthesia/Intensive Care Unit, Department of Pediatric Cardiology and Cardiac Surgery, Bambino Gesù Children's Hospital, IRCCS, Piazza S.Onofrio 4, 00165, Rome, Italy. ${ }^{2}$ Cardio-Vascular Anesthesia and Post-Surgical Intensive Care Unit, Heart and Vessels Department, Azienda Ospedaliero-Universitaria Careggi, Largo Brambilla, 3 - 50134, Florence, Italy. 3Pediatric Nephrology Unit, Department of Pediatric Nephrology, Dialysis and Transplantation, Bambino Gesù Children's Hospital, IRCCS, Piazza S.Onofrio 4, 00165, Rome, Italy.

\section{Published: 8 November 2012}

\section{References}

1. Chawla LS, Kellum JA, Ronco C: Permissive hypofiltration. Crit Care 2012, 16:317.

2. Tremblay LN, Slutsky AS: Ventilator-induced lung injury: From the bench to the bedside. Intensive Care Med 2006, 32:24-33.

3. Elseviers MM, Lins RL, Van der Niepen P, Hoste E, Malbrain ML, Damas P, Devriendt J; SHARF investigators: Renal replacement therapy is an independent risk factor for mortality in critically ill patients with acute kidney injury. Crit Care 2010, 14:R221.

4. Ronco C, Garzotto F, Ricci Z: CA.R.PE.DI.E.M. (Cardio-Renal Pediatric Dialysis 
Emergency Machine): evolution of continuous renal replacement therapies in infants. A personal journey. Pediatr Nephrol 2012, 27:1203-1211.

5. Bagshaw SM, Gibney RT, McAlister FA, Bellomo R: The SPARK Study: A phase II randomized blinded controlled trial of the effect of furosemide in critically ill patients with early acute kidney injury. Trials 2010, 11:50.

6. Terragni PP, Del Sorbo L, Mascia L, Urbino R, Martin EL, Birocco A, Faggiano C, Quintel M, Gattinoni L, Ranieri VM: Tidal volume lower than $6 \mathrm{ml} / \mathrm{kg}$ enhances lung protection: role of extracorporeal carbon dioxide removal. Anesthesiology 2009, 111:826-835. doi:10.1186/cc11494

Cite this article as: Ricci Z, et al:: Permissive hypofiltration: an alternative view. Critical Care 2012, 16:458. 